\title{
Effect of bone marrow-derived mesenchymal stem cells on hepatic fibrosis in a thioacetamide-induced cirrhotic rat model
}

\author{
Yoon Ok Jang ${ }^{1 \dagger}$, Moon Young Kim ${ }^{1 \dagger}$, Mee Yon Cho ${ }^{2}$, Soon Koo Baik ${ }^{1 *}$, Youn Zoo Cho ${ }^{1}$ and Sang Ok Kwon ${ }^{1}$
}

\begin{abstract}
Background: Cirrhosis is a long-term consequence of chronic hepatic injury with fibrosis. No effective therapy is currently available for decompensated cirrhosis except liver transplantation. Hence, we investigated the effect of bone marrow-derived mesenchymal stem cells (BM-MSCs) on hepatic fibrosis in a thioacetamide (TAA)-induced cirrhotic rat model.

Methods: The BM-MSCs were injected directly into the right liver lobe twice, at 6 and 8 weeks during the 12-week TAA administration, in thioacetamide (TAA)-induced cirrhotic rats model, and hepatic fibrosis was evaluated. At 12 weeks, the effect of BM-MSCs on hepatic fibrosis was analyzed histomorphologically using the Laennec fibrosis scoring system, and the collagen proportionate area was quantified. Cirrhosis-related factors, such as transforming growth factor $\beta 1$ (TGF- $\beta 1$ ), type 1 collagen (collagen-1), a-smooth muscle actin (a-SMA), and P-Smad3/Smad3 expression levels, were evaluated using real-time polymerase chain reaction and western blot assays.

Results: According to the Laennec fibrosis scoring system, histological improvement was observed in hepatic fibrosis after BM-MSC treatment $(P<0.01)$. The percentage of the collagen proportionate area decreased from $16.72 \pm 5.51$ to $5.06 \pm 1.27$ after BM-MSC treatment $(P<0.01)$. The content of hepatic hydroxyproline was significantly lower in the BM-MSC treated group (46.25 \pm 13.19$)$ compared to the untreated cirrhotic group $(85.81 \pm 17.62 ; P<0.01)$. BM-MSC administration significantly decreased TGF- $\beta 1$, collagen-1, and a-SMA expression in TAA-induced cirrhotic rats $(P<0.01)$. We also confirmed P-Smad3/Smad3, downstream effectors of the TGF- $\beta 1$ signaling pathway, and found that MSC transplantation inhibited Smad3 phosphorylation.
\end{abstract}

Conclusions: BM-MSC treatment attenuated hepatic fibrosis in rats with TAA-induced cirrhosis, raising the possibility of the clinical use of BM-MSCs in the treatment of cirrhosis.

Keywords: Bone marrow-derived mesenchymal stem cell, Cirrhosis, Hepatic fibrosis, Liver function

\section{Background}

Cirrhosis, the end stage of progressive hepatic fibrosis, is characterized by distortion of the hepatic architecture and the formation of regenerative nodules, angiogenesis, and shunts, leading to loss of liver function and the development of hepatocellular carcinoma [1-6]. The most effective therapy for advanced cirrhosis is currently liver transplantation. However, this procedure has several

\footnotetext{
* Correspondence: baiksk@yonsei.ac.kr

${ }^{\dagger}$ Equal contributors

'Department of Internal Medicine, Yonsei University, Wonju College of

Medicine, 162, Ilsan-dong, Wonju, Republic of Korea

Full list of author information is available at the end of the article
}

limitations, including a lack of donors, surgical complications, immunological suppression, and a high medical cost [7]; thus, there is a need for a new therapeutic paradigm in this field.

Cell-based therapy, such as hepatocyte transplantation, has been considered a potential alternative to liver transplantation. Alternative therapeutic approaches that circumvent the use of the whole organ, such as the transplantation of cells of various origins, have recently been accepted $[8,9]$. In addition, stem cell transplantation has been suggested as an effective alternate therapy for hepatic disease $[10,11]$. Several previous studies using 
animal models of liver diseases have demonstrated that bone marrow (BM) cell transplantation may accelerate the liver regeneration process, reduce hepatic fibrosis, and improve liver function and survival [12-15]. The prospects for stem cell transplantation as a therapy for hepatic disease, as determined by initial translational pilot studies testing the direct hepatic administration of BM-derived stem cells, have been encouraging and have suggested enhanced liver regeneration prior to partial hepatectomy and improved liver function in advanced chronic liver disease [16-22]. Among the stem cells, mesenchymal stem cells (MSCs) in particular have practical advantages in regenerative medicine due to their high capability for selfrenewal, their potential for multipotent differentiation, and their low immunogenicity. In addition, previous studies have demonstrated that bone marrow-derived mesenchymal stem cells (BM-MSCs) might be involved in the regression of liver fibrosis [23,24].

Concomitantly, transforming growth factor (TGF)- $\beta 1$ is a key mediator of fibrogenesis [25], and the TGF- $\beta 1$ signaling pathway contributes to liver fibrosis progression [26]. More importantly, TGF- $\beta 1$ mediates its biological functions via the canonical Smad pathway by activating the transmembrane receptors that stimulate the cytoplasmic Smad proteins, which in turn activate collagen transcription [26,27]. Therefore, the TGF- $\beta 1$ activated Smad3 signaling pathway is critical for the development of hepatic fibrosis, and TGF- $\beta$ signaling pathways are potential therapeutic targets for liver fibrosis [27-29].

BM-MSCs can be easily harvested from bone marrow, expanded ex vivo, and differentiated into many cell type lineages, if desired. Because of their immunotolerance, the establishment of MSCs as effective universal donor cells [30] could then dramatically expand their therapeutic potential for cellular cardiomyoplasty. Despite the initial hope that BM-MSCs could feature an immune privilege, it is now increasingly recognized that these cells trigger an immune reaction that leads to their rejection in both allogeneic and xenogeneic settings. In fact, a number of laboratories have recently reported that MSCs may have a unique immunological property capable of inducing tolerance in immunocompetent allotransplant or even xenotransplant recipients [31]. The mechanisms of such immunotolerance have been the subject of intense study, and three interrelated candidate mechanisms are emerging [30,32]. MSCs appear to evade rejection by being hypoimmunogenic, modulating T-cell phenotypes, and immunosuppressing the local environment.

In this study, we investigated the effect of BM-MSCs on hepatic fibrosis in a thioacetamide (TAA)-induced cirrhotic rat model and the underlying mechanism by which BM-MSCs ameliorate hepatic fibrosis.

\section{Methods}

\section{Preparation of human bone marrow-derived mesenchymal} stem cells

Human BM-MSCs were obtained from healthy persons who voluntarily donated their bone marrow stem cells. Approximately $10-20 \mathrm{~mL}$ of $\mathrm{BM}$ was aspirated from the posterior iliac crests of humans under local anesthesia. BM mononuclear cells were isolated through densitygradient centrifugation (Histopaque-1077, Sigma-Aldrich, St. Louis, MO, USA). Mononuclear cells $\left(2-3 \times 10^{5}\right.$ cells/ $\mathrm{cm}^{2}$ ) were plated in a $75-\mathrm{cm}^{2}$ flask (Falcon, Franklin Lakes, NJ, USA) with Dulbecco's modified Eagle's medium (DMEM; Gibco, Grand Island, NY, USA) containing 10\% fetal bovine serum (FBS; Gibco) and 1\% penicillin/ streptomycin (Gibco) and then cultured at $37^{\circ} \mathrm{C}$ in a $5 \%$ $\mathrm{CO}_{2}$ atmosphere. When the cultures approached $80 \%$ confluence, the cells were harvested by treatment with a trypsin/EDTA solution (Gibco) and replated at a density of $4-5 \times 10^{3}$ cells $/ \mathrm{cm}^{2}$ in $175-\mathrm{cm}^{2}$ flasks. Cells for injection were serially subcultured to passage four or five. The human procedures and protocols were approved by the Institutional Review Board (IRB) at Yonsei University Wonju Severance Hospital (CR109021), and conducted according to the principles of the Declaration of Helsinki. All participants provided written informed consent prior to participation in the study.

\section{Immunophenotypes and differentiation assays of BM-MSCs}

The immunophenotypes of the BM-MSCs (CD14, CD34, CD45, CD73, and CD105) were analyzed on the day of injection, and their differentiation potentials were determined (osteogenesis and adipogenesis; Figure 1). For the immunophenotype analysis, BM-MSCs were stained with antibodies conjugated with fluorescein isothiocyanate (FITC) or phycoerythrin (PE): CD14-FITC, CD34-FITC, CD45-FITC, CD73-PE, and CD105-PE (BD Biosciences, San Jose, CA, USA). Briefly, $5 \times 10^{5}$ cells were resuspended in $0.2 \mathrm{~mL}$ of phosphate-buffered saline (PBS) and incubated with FITC- or PE-conjugated antibodies for $20 \mathrm{~min}$ at room temperature. FITC- or PE-conjugated mouse IgGs were used as the control isotype at the same concentration as the specific primary antibodies. The fluorescence intensity of the cells was evaluated through flow cytometry (Epics XL; Beckman Coulter, Miami, FL, USA). Osteogenic differentiation was determined by first plating the cells at $2 \times 10^{4}$ cells $/ \mathrm{cm}^{2}$ in six-well plates and then incubating them in the following osteogenic medium for 2-3 weeks: DMEM medium supplemented with 10\% FBS, $10 \mathrm{mM} \beta$-glycerophosphate, $10^{-7} \mathrm{M}$ dexamethasone, and $0.2 \mathrm{mM}$ ascorbic acid (Sigma-Aldrich) [33]. The osteogenic differentiation was quantified from the release of p-nitrophenol from p-nitrophenyl phosphate by the enzyme alkaline phosphatase [34]. For adipogenic 


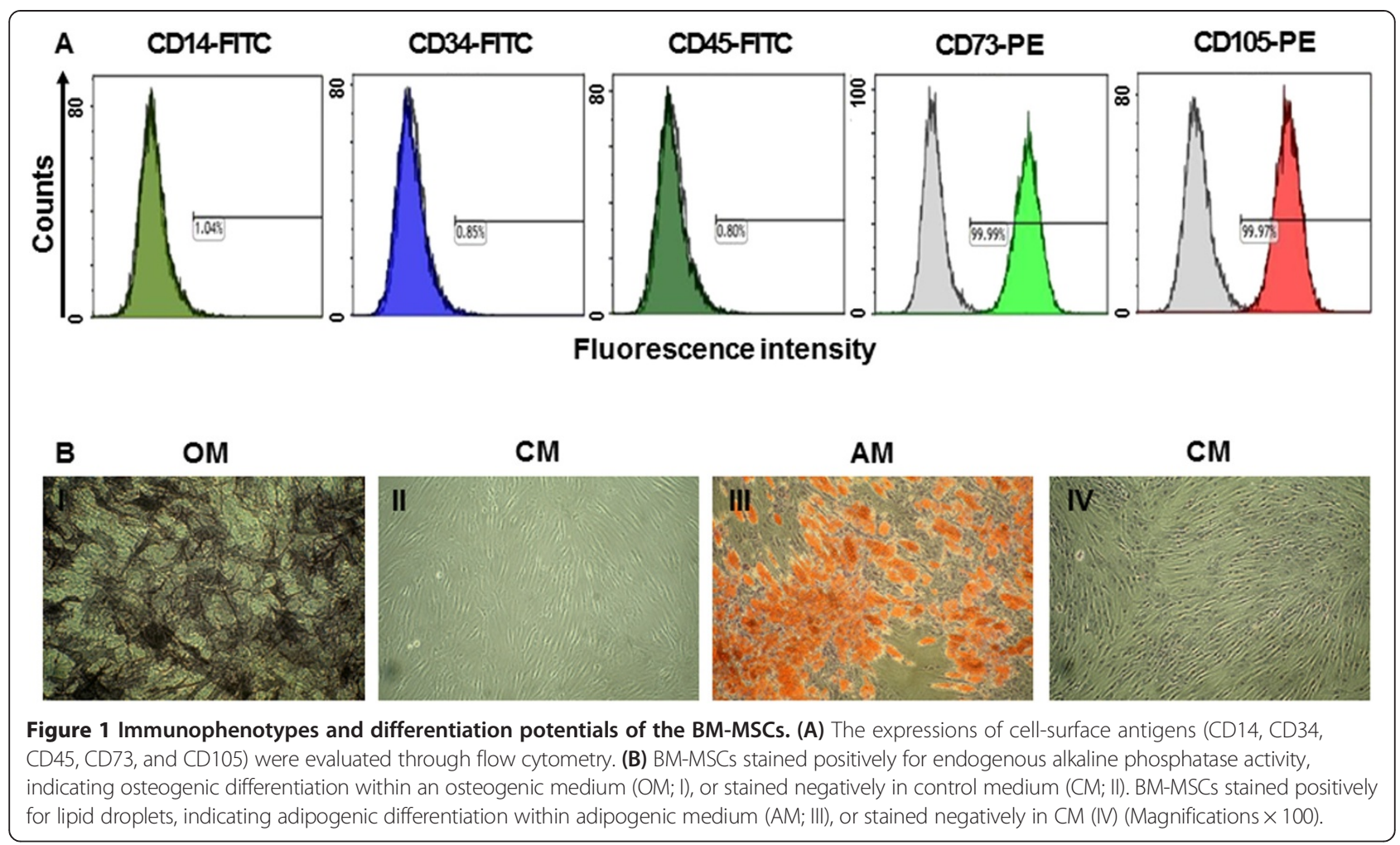

differentiation, BM-MSCs were plated at $2 \times 10^{4}$ cells/ $\mathrm{cm}^{2}$ in six-well plates and cultured for 1 week; then, differentiation was induced with adipogenic medium $(10 \%$ FBS, $1 \mu \mathrm{M}$ dexamethasone, $0.5 \mathrm{mM}$ 3-isobutyl-1-methylxanthine, $10 \mu \mathrm{g} / \mathrm{mL}$ insulin, and $100 \mu \mathrm{M}$ indomethacin in high-glucose DMEM) for an additional 3 weeks. The differentiated cells were fixed in $4 \%$ paraformaldehyde for $10 \mathrm{~min}$ and stained with fresh Oil Red-O solution (Sigma-Aldrich) to display lipid droplets (Figure 1B). The criteria regarding the use of MSCs included viability greater than $80 \%$; the absence of microbial contamination (bacteria, fungus, virus, or mycoplasma) when tested 3-4 days before administration; CD73 and CD105 expression in more than $90 \%$ of the cells; and the absence of CD14, CD34, and CD45 in less than 3\% of the cells, as assessed by flow cytometry.

\section{Induction of hepatic fibrosis and BM-MSC treatment in a thioacetamide-induced cirrhotic rat model}

Seven-week-old male Sprague-Dawley rats (Orient Bio Inc.) were maintained at a room temperature of $25^{\circ} \mathrm{C}$ with a 12/12-h light/dark cycle and with free access to food and water throughout the 12-week experiment. Hepatic fibrosis was induced in Sprague-Dawley rats by intraperitoneal (i.p.) injections of TAA (Sigma, St. Louis, $\mathrm{MO}$, USA; $300 \mathrm{mg} / \mathrm{kg}$ body weight) twice a week for 12 weeks. The animals were randomly allocated into three groups (each group, $n=18$ ) as follows: Group I (G1, sham group); Group II (G2, untreated cirrhotic group), which received the TAA injection; and Group III (G3, BM-MSC treated group), which received the TAA injection and the BM-MSC treatment. The rats were anesthetized by intramuscular administration with a mixture of Zoletil ${ }^{\circ}$ (Virbac Laboratories, Carros, France) and Rompun (Bayer Korea, Seoul, Korea). With aseptic techniques, a 1-cm incision was made caudal to the costal arch on the right flank to expose the right lobe of the liver. With a syringe, $2 \times 10^{6}$ human BM-MSCs were injected directly into the right lobe of the liver at 6 and 8 weeks during the 12-week TAA administration in the BM-MSC treated group (Figure 2). At 12 weeks, the animals were sacrificed after taking blood samples, and liver tissue specimens were collected, fixed, and immediately snap-frozen and stored at $-80^{\circ} \mathrm{C}$ for analysis. The animal experimental procedures and protocols were approved by the Institutional Animal Care and Use Committee (IACUC) at Yonsei University Wonju College of Medicine (YWC-131008-1).

\section{Histomorphological and immunohistochemical analysis}

Five-micrometer-thick sections of paraffin-embedded liver tissues were prepared and stained with hematoxylin and eosin (H\&E), Masson's trichrome (MTC), $\alpha$-smooth muscle actin ( $\alpha$-SMA), and Picrosirius Red. Fibrosis was evaluated using the Laennec fibrosis scoring system (Table 1). In the Laennec system, the thickness of the predominant type of septae in each specimen is chosen, and the smallest nodule 


\section{BM-MSCs injection into the right lobe of the liver}

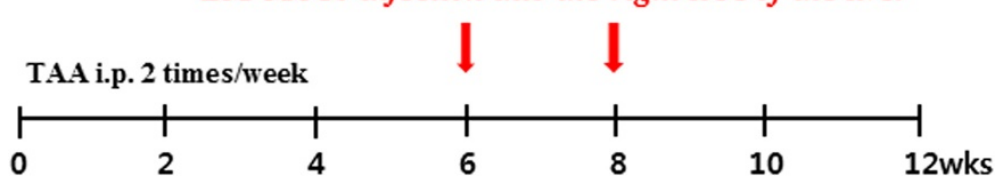

Figure 2 Experimental design of BM-MSCs injection. Hepatic fibrosis was induced in Spraque-Dawley rats by intraperitoneal (i.p.) injections of TAA (300 mg/kg) twice a week for 12 weeks. The BM-MSCs were injected directly into the right liver lobe twice, at 6 and 8 weeks during the 12-week TAA administration.

is selected for scoring. A liver pathologist who was blinded to the clinical data evaluated fibrosis simultaneously and prospectively. The Laennec fibrosis scoring system was used because this system divides cirrhosis into three subclasses, allowing for a more detailed estimation of fibrosis after intervention [35]. In addition, to estimate any treatment-induced changes in liver fibrosis, the fibrosis area was quantified as a percentage of the total area that was positive for MTC stain in the digital photomicrographs using a computerized image analysis system (Analysis 3.0, Soft Imaging System, Münster, Germany). To quantify the fibrosis area, microscopic areas were selected randomly at an original magnification of $100 \mathrm{X}$. For immunohistochemical analysis, the tissue sections were incubated with primary antibody against $\alpha$-SMA (diluted 1:800; Neomarkers, Fremont, CA, USA) for $90 \mathrm{~min}$ at room temperature after washing with buffer. The tissue sections were incubated with the chromogen 3-amino-9ethylcarbazole (BioGenex, San Ramon, CA, USA) for 5-7 min. Prior to mounting, the sections were counterstained with hematoxylin and then dehydrated. An UltraVision LP Large Volume Detection System (Lab Vision, Runcorn, UK) was used as the detection system. Morphological analysis of immunopositive cells was also performed using a computerized image analysis system.
Picrosirius Red staining was performed to quantify the total amount of collagen. Five-micrometer-thick sections of paraffin-embedded liver tissues were deparaffinized and rehydrated with distilled water and stained with a Picrosirius Red staining kit (Polysciences, Warrington, PA, USA) according to the manufacturer's instructions. In addition, the amount of collagen (the main component of fibrous tissue) was estimated from the collagen proportionate area and expressed as the percentage of the total area that was positive for Picrosirius Red stain on microscopy (Olympus BX51, Tokyo, Japan) using a computerized image analysis program (IMT i solution, Vancouver, Canada). While measuring the collagen proportionate area, we eliminated image artifacts and structural collagen in large portal tracts and blood vessel walls [36].

\section{Hepatocyte differentiation and identification of BM-MSCs}

The expression of hepatocyte specific marker (Albumin) was analyzed at 7 and 14 days after $2 \times 10^{6}$ human BMMSCs were injected directly into the right lobe of the liver in TAA-induced hepatic fibrosis rats. Five-micrometerthick sections of liver tissues were incubated with human anti-albumin antibody (A6684; Sigma) at $4^{\circ} \mathrm{C}$ overnight. The slides were washed and incubated with Alexa Fluor ${ }^{\circ}$ 488 (Invitrogen, Carlsbad, CA) secondary antibody for $1 \mathrm{hr}$ in dark. The nuclei were stained with Hoechst.

Table 1 Laennec scoring system for staging fibrosis in liver specimens

\begin{tabular}{|c|c|c|c|c|}
\hline Stage & Name & $\begin{array}{l}\text { Septa (thickness } \\
\text { and number) }\end{array}$ & Criteria & Score \\
\hline 0 & No definite fibrosis & & & 0 \\
\hline 1 & Minimal fibrosis & $+/-$ & $\begin{array}{l}\text { No septa or rare thin septum; may have portal expansion or mild } \\
\text { sinusoidal fibrosis }\end{array}$ & 1 \\
\hline 2 & Mild fibrosis & + & Occasional thin septa; may have portal expansion or mild sinusoidal fibrosis & 2 \\
\hline 3 & Moderate fibrosis & ++ & Moderate thin septa; up to incomplete cirrhosis & 3 \\
\hline $4 \mathrm{~A}$ & Mild, definite, or probable cirrhosis & +++ & $\begin{array}{l}\text { Marked septation with rounded contours or visible nodules. Most septa } \\
\text { are thin (one broad septum allowed) }\end{array}$ & 4 \\
\hline $4 \mathrm{~B}$ & Moderate cirrhosis & ++++ & $\begin{array}{l}\text { At least two broad septa, but not very broad septa and less than half of } \\
\text { biopsy length composed of minute nodules }\end{array}$ & 5 \\
\hline $4 C$ & Severe cirrhosis & +++++ & $\begin{array}{l}\text { At least one very broad septum or more than half of biopsy length } \\
\text { composed of minute nodules (micronodular cirrhosis) }\end{array}$ & 6 \\
\hline
\end{tabular}


Fluorescence images were showed under a laser scanning confocal microscope (TCS SPE, Leica Microsystems $\mathrm{GmbH}$, Wetzlar, Germany). To identify injected BMMSCs in the hepatic fibrosis rat liver, BM-MSCs were labeled with fluorescent spherical silica nanoparticles with CELL-STALKER ${ }^{\mathrm{TM}}$-CSR (Biterials) that contained Rhodamine $B$ isothiocyanate (RITC) according to manufacturer's protocol. CELL-STALKER was centrifuged at $12,000 \mathrm{rpm}$ for $10 \mathrm{~min}$ then supernatant was discarded except pellet and sonicated for $5 \mathrm{~min}$ at 40 khz-300 $\mathrm{w}$ to evenly distribute particles, placed into BM-MSCs culturing $75 \mathrm{~T}$ flask and incubated at $37^{\circ} \mathrm{C}$ for 24 hrs. After incubation, the cells were harvested by treatment with a trypsin/EDTA solution. The $2 \times 10^{6}$ BM-MSCs labeled with CELL-STALKER were injected directly into the right lobe of the liver in TAA-induced hepatic fibrosis rats and fluorescence images for BM-MSCs were showed under a laser scanning confocal microscope at $0,3,7,14$ days.

\section{Biochemical analysis}

Measurement of alanine transaminase (ALT), aspartate transaminase (AST), total bilirubin, and albumin levels were carried out using commercially available kits (Asan Pharmaceutical, Republic of Korea) according to manufacturer's instructions.

\section{Quantitative real-time PCR analysis}

Total RNA was isolated from liver tissues using TRIzol reagent (Invitrogen, Carlsbad, CA, USA) according to the manufacturer's protocol. RNA purity and concentration were determined using a spectrophotometer (Ultrospec 2100 pro UV/Visible, Amersham Bioscience, Freiburg, Germany). cDNA was synthesized from total RNA $(1 \mu \mathrm{g})$ using the GeneAmp RNA PCR Kit (Applied Biosystems, Foster City, CA, USA) with oligo-dT (Applied Biosystems). For the real-time polymerase chain reaction (PCR), amplification was performed to measure the mRNA levels of TGF- $\beta 1$, type 1 collagen (collagen- 1 ), and $\alpha$-SMA using sequence-specific primers (Table 2). Quantitative realtime PCR using SYBR Green PCR Master Mix (Applied Biosystems) was performed in an ABI PRISM 7900HT Sequence Detection System (Applied Biosystems) according to the manufacturer's instructions. The data were analyzed using SDS 2.2.2 software (Applied Biosystems). The cycle threshold $(\mathrm{Ct})$ values of the target genes were normalized to the $\mathrm{Ct}$ values of the endogenous control (glyceraldehyde-3phosphate dehydrogenase). Relative changes were calculated using the equation $2^{-\Delta \Delta C t}$.

\section{Hepatic hydroxyproline content}

Liver tissues were hydrolyzed with $6 \mathrm{~N} \mathrm{HCl}$ at $120^{\circ} \mathrm{C}$ for 16 hrs. The hydrolysate was then cooled,
Table 2 Primer sequences for quantitative PCR

\begin{tabular}{lll}
\hline Gene & Forward/reverse & Primer sequence \\
\hline GAPDH & Forward & AGCCCAGAACATCATCCCTG \\
& Reverse & CACCACCTTCTTGATGTCATC \\
TGF- 31 & Forward & CCTGGAAAGGGCTCAACAC \\
& Reverse & CAGTTCTCTCTGTGGAGCTGA \\
Collagen-1 & Forward & CATGTTCAGCTITGTGGACCT \\
& Reverse & GCAGCTGACTTCAGGGATGT \\
a-SMA & Forward & CGATAGAACACGGCATCATCAC \\
& Reverse & GCATAGCCCTCATAGATAGGCA \\
\hline
\end{tabular}

GAPDH, glyceraldehyde-3-phosphate dehydrogenase; TGF- $\beta 1$, transforming growth factor-beta 1; collagen-1, type 1 collagen; a-SMA, a-smooth muscle actin.

neutralized with $6 \mathrm{~N} \mathrm{NaOH}$, and centrifuged at $13,000 \mathrm{~g}$ for $10 \mathrm{~min}$. The supernatants were supplemented with $7 \%$ chloramine $\mathrm{T}$, acetate/citrate buffer (sodium acetate $3 \mathrm{H}_{2} \mathrm{O}$, trisodium citrate $2 \mathrm{H}_{2} \mathrm{O}$, citric acid, with isopropanol). Ehrlich's solution (dimethylaminobenzaldehyde with perchloric acid and isopropanol) was then added and incubated at $60^{\circ} \mathrm{C}$ for $35 \mathrm{~min}$. After cooling, absorbance was measured at $560 \mathrm{~nm}$ with an Emax Precision Microplate Reader (Molecular Devices, Sunnyvale, CA, USA). Hydroxyproline concentration was calculated from a standard curve prepared with hydroxyproline (Sigma, H5534). The results were expressed as micrograms of hydroxyproline per gram of liver tissue.

\section{Western blot assays}

For total protein extracted from liver tissues, tissues were homogenized using a TissueLyser II (QIAGEN GmbH, Haan, Germany) with a tissue protein extraction reagent (T-PER; Pierce, Rockford, IL, USA). The lysates were centrifuged at $13,000 \mathrm{rpm}$ for $15 \mathrm{~min}$ at $4^{\circ} \mathrm{C}$, and the protein concentrations of the supernatants were determined using a protein assay kit (Bio-Rad Laboratories Inc., Hercules, CA). Thirty micrograms of each liver protein was electrophoresed on a $10 \%$ sodium dodecyl sulfate-polyacrylamide (SDS-PAGE) gel and then transferred to polyvinylidene difluoride (PVDF) membranes (Millipore, Bedford, MA, USA). The membranes were blocked with $5 \%$ skim milk in Tris-Buffered Saline (TBS) containing 0.1\% Tween-20 for $1 \mathrm{hr}$ at room temperature, and the membranes were then incubated with primary antibodies at $4^{\circ} \mathrm{C}$ overnight. The primary antibodies were as follows: TGF- $B 1$ (Abcam, Cambridge, MA, USA), $\alpha$-SMA (Abcam), Smad3 (Cell Signaling Technology, Danvers, MA, USA), and phospho Smad3 (Cell Signaling Technology). Horseradish peroxidase (HRP)-conjugated secondary antibodies against either mouse IgG (Abcam) or rabbit IgG (Cell Signaling Technology) were incubated for $1 \mathrm{hr}$ at room temperature. 
Specific protein bands on the membranes were developed using an enhanced chemiluminescence (ECL) detection kit (Amersham, Piscataway, NJ, USA). To normalize between experiments, the membranes were probed with a $\beta$ actin antibody (Abcam), and the intensity of each protein band was normalized to the intensity of $\beta$-actin.

\section{Statistical analysis}

The values are expressed as means \pm standard deviations. Nonparametric analysis was performed with the KruskalWallis $H$ test. Statistical analysis was performed using SPSS software version 20.0 (SPSS, Chicago, IL, USA). For all tests, $P$ values $<0.01$ were considered significant.

\section{Results}

Immunophenotypes and differentiation potentials of the BM-MSCs

The immunophenotypes for CD14, CD34, CD45, CD73, and CD105 cells were determined, and osteogenic or adipogenic differentiation was induced on the day of BMMSC injection (Figure 1). In both the first and second injected cell populations, CD73 or CD105 (which are positive markers of BM-MSCs) were expressed in more than 98\% of the cells. However, CD14, CD34, and CD45 (which are known to be negative markers of BM-MSCs) were expressed in less than $1 \%$ of the cells (Figure 1). Therefore, the BM-MSCs were differentiated into osteocytes and adipocytes (Figure 1B).

\section{Histological and immunohistochemical analysis}

The Laennec fibrosis scoring system revealed detailed individual changes within the cirrhotic tissue (F4A-F4C; Table 1). Histological analysis was evaluated by $\mathrm{H} \& \mathrm{E}$ and MTC staining (Figure 3). In the untreated cirrhotic group, the liver sections were strongly stained by $\mathrm{H} \& \mathrm{E}$ and MTC, showing definite cirrhosis (stage 4 fibrosis) with regenerating nodules and fibrous septae (Figure 3A), whereas the BM-MSC treated group showed mild fibrosis (Figure 3B). To compare these findings, the degree of fibrosis was scored according to the Laennec fibrosis scoring system. The BM-MSC treated group had a significantly lower mean score than that of the untreated cirrhotic group. According to the Laennec fibrosis system, histologically, the BM-MSC treated group showed significant improvement in hepatic fibrosis compared to the untreated cirrhotic group $(P<0.01)$. These results were further confirmed by immunohistochemical staining revealing $\alpha$-SMA expression and Picrosirius Red stain (Figure 3). The relative expression of the collagen proportionate area stained by Picrosirius Red was analyzed using an image analysis program. The percentage of the collagen proportionate area significantly decreased from $16.72 \pm 5.51$ to $5.06 \pm 1.27$ after BM-MSC treatment $(P<0.01$; Figure $3 \mathrm{G})$. In addition, the analysis of histopathological fibrosis scoring confirmed that cirrhosis was significantly reduced by BM-MSCs treatment, compared to the untreated cirrhotic group (Table 3).

\section{Hepatocyte differentiation and identification of BM-MSCs}

To investigated whether BM-MSCs are capable of undergoing hepatic differentiation, the expression of albumin was detected by immunofluorescence staining. At 7 days after BM-MSCs injection, expression of albumin was weakly detected. However, intensity of albumin staining was stronger at 14 days (Figure 4 ).

To identify injected BM-MSCs to the hepatic fibrosis rat liver, fluorescence red labeled BM-MSCs were showed at $0,3,7,14$ days after direct injection in hepatic fibrosis rat liver. Fluorescence intensity from labeled BM-MSCs was maintained for 14 days in liver tissue. However fluorescence intensity from labeled BM-MSCs was gradually reduced and disappeared at 14 days (Additional file 1: Figure S1).

Differentiation of BM-MSCs into hepatocytes was determined by immunofluorescence staining using albumin antibody and identification of BM-MSCs in hepatic fibrosis was determined by fluorescent microscopy using CELL STALKER-CSR dye staining. Consequently, we showed that fluorescence intensity from labeled BM-MSCs with CELL-STALKER was gradually disappeared and albuminstained areas had gradually expanded at 14 days after injection, considering that BM-MSCs had transdifferentiated into hepatocytes after injection. Based on these results, it may suggested that BM-MSCs had transdifferentiated into hepatocytes after injecting hepatic fibrosis rats.

\section{Biochemical analysis}

The serum levels of ALT, AST, and total bilirubin were significantly decreased in BM-MSCs treated group. In addition, serum level of albumin in the BM-MSC treated group were increased compared to the untreated cirrhotic group $(P<0.01$; Figure 5$)$.

\section{TGF- $\beta 1$, collagen- 1 , and $\alpha$-SMA mRNA levels}

After BM-MSC administration, the mRNA relative expression levels of TGF- $\beta 1$, collagen- 1 , and $\alpha$-SMA were determined through quantitative real-time reverse transcription-PCR (RT-PCR) analysis. The collagen-1 mRNA relative expression levels were $1 \pm 0.39,14.04 \pm$ 4.54, and 4.74 $\pm 2.46(P<0.01)$ in G1, G2, and G3, respectively (Figure $6 \mathrm{~B}$ ). In addition, the TGF- $\beta 1$ and $\alpha$-SMA mRNA relative expression levels were $1 \pm 0.27$, $4.61 \pm 0.61$, and $2.14 \pm 0.35(P<0.01)$ and $1 \pm 0.32,8.83$ \pm 3.12 , and $2.62 \pm 0.41(P<0.01)$ in G1, G2, and G3, respectively (Figure 6A, 6C). The TGF- $\beta 1$, collagen-1, and $\alpha$-SMA mRNA relative expression levels in the BMMSC treated group were significantly decreased compared to the untreated cirrhotic group $(P<0.01)$. 

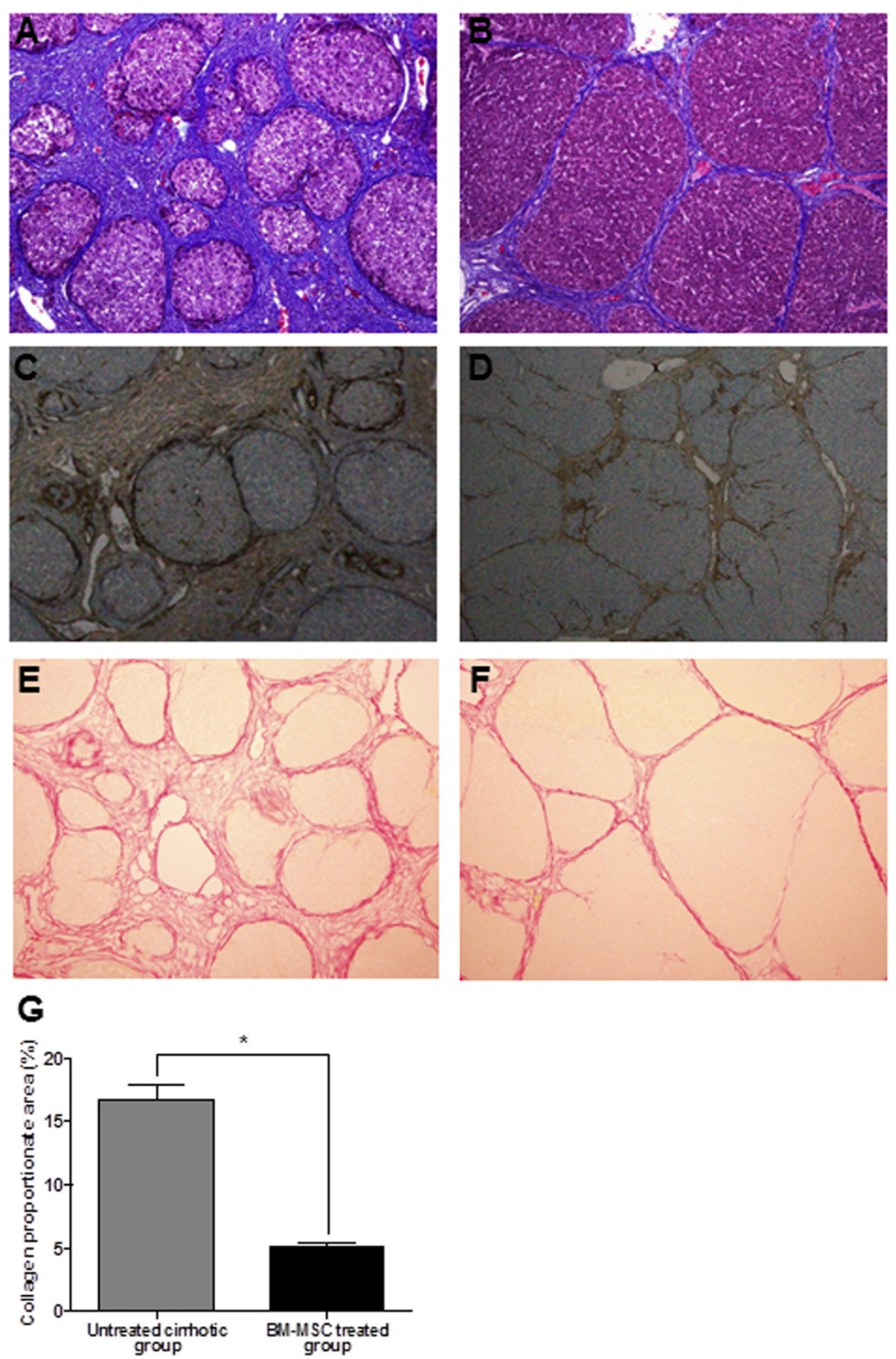

Figure 3 Histological analysis and the relative expression of the collagen proportionate area. Histological analysis was evaluated by MTC $(\mathbf{A}, \mathbf{B})$, a-SMA (C, D), and Picrosirius Red staining (E, F). BM-MSC treatment induced an improvement of cirrhosis from F4C (A, C, E) to F4A (B, D, F) according to the Laennec fibrosis scoring system. Untreated cirrhotic group (A, C) show cirrhosis with at least one broad septum with minute nodules (F4C) and BM-MSC treated group (B, D) show cirrhosis with marked septation with rounded contours or visible large nodules (F4A). Picrosirius Red staining of a section from a liver biopsy specimen showed a change in collagen proportion stained as red from untreated cirrhotic group (E) to BM-MSC treated group $(\mathbf{F})$. The relative area of collagen stained by Picrosirius Red was analyzed with an image analysis program (G). The percentage of the collagen proportionate area decreased from $16.72 \pm 5.51$ to $5.06 \pm 1.27$ after BM-MSC treatment $(P<0.01)$. (Magnifications $\times 100$ ). Values are expressed as means \pm SD. ${ }^{*} P<0.01$. 
Table 3 Histological stage of hepatic fibrosis

\begin{tabular}{lllllllll}
\hline Group & Stage $\mathbf{0}$ & Stage $\mathbf{1}$ & Stage 2 & Stage 3 & Stage 4A & Stage 4B & Stage 4C & Average \\
\hline Score & 0 & 1 & 2 & 3 & 4 & 5 & 6 & 0 \\
G1 & 18 & & & & 2 & 7 & 9 \\
G2 & & & 2 & 7 & 6 & 3 & 3.4 \\
G3 & & & & & & & 3 \\
\hline
\end{tabular}

Group I (G1, sham group); Group II (G2, untreated cirrhotic group); Group III (G3, BM-MSC treated group).

\section{Measurement of hepatic hydroxyproline content}

The content of hepatic hydroxyproline was quantified colorimetrically from liver tissues. Quantitative analysis showed that the contents of hepatic hydroxyproline of the liver tissue were $16.44 \pm 4.07,85.81 \pm 17.62$, and $46.25 \pm 13.19(P<0.01)$ in $\mathrm{G} 1, \mathrm{G} 2$, and G3, respectively (Figure 6D). The content of hepatic hydroxyproline was significantly lower in the BM-MSC treated group than in the untreated cirrhotic group.

\section{TGF- $\beta 1$ and $\alpha-S M A$ protein expression levels}

The TGF- $\beta 1$ and $\alpha$-SMA protein expression levels were measured through western blot assays (Figure 7). The TGF- $\beta 1$ and $\alpha$-SMA protein expression levels were $1 \pm$ $0.15,2.5 \pm 0.39$, and $1.41 \pm 0.41(P<0.01)$ and $1 \pm 0.14$, $1.8 \pm 0.49$, and $1.16 \pm 0.25(P<0.01)$ in G1, G2, and G3, respectively (Figure 7 ). The TGF- $\beta 1$ and $\alpha$-SMA protein expression levels in the BM-MSC treated group were significantly decreased compared to the untreated cirrhotic group $(P<0.01)$.
We examined the effect of BM-MSCs on the status of Smad3 and found that Smad3 phosphorylation was markedly increased in the untreated cirrhotic group but was significantly decreased after BM-MSC treatment. These results demonstrate that BM-MSCs modulated the TGF$\beta 1 /$ Smad signaling pathway by attenuating TGF- $\beta 1$ and Smad3 expression and inhibiting Smad3 phosphorylation.

\section{Discussion}

In this study, we investigated the effect of BM-MSCs on hepatic fibrosis in a TAA-induced cirrhotic rat model and explained the fundamental mechanism of hepatic fibrosis attenuation caused by BM-MSC treatment. The major findings of our study are as follows: (1) administration of MSCs at $2 \times 10^{6}$ cells into TAA-induced cirrhotic rat livers via direct injection allowed recovery from TAAinduced fibrosis at 4 weeks after BM-MSC treatment; (2) BM-MSCs recovered liver function through decreases in TGF- $\beta 1$, collagen- 1 , and $\alpha$-SMA expression; and (3) BMMSCs led to the recovery of liver function via the TGF$\beta 1 /$ Smad signaling pathway.

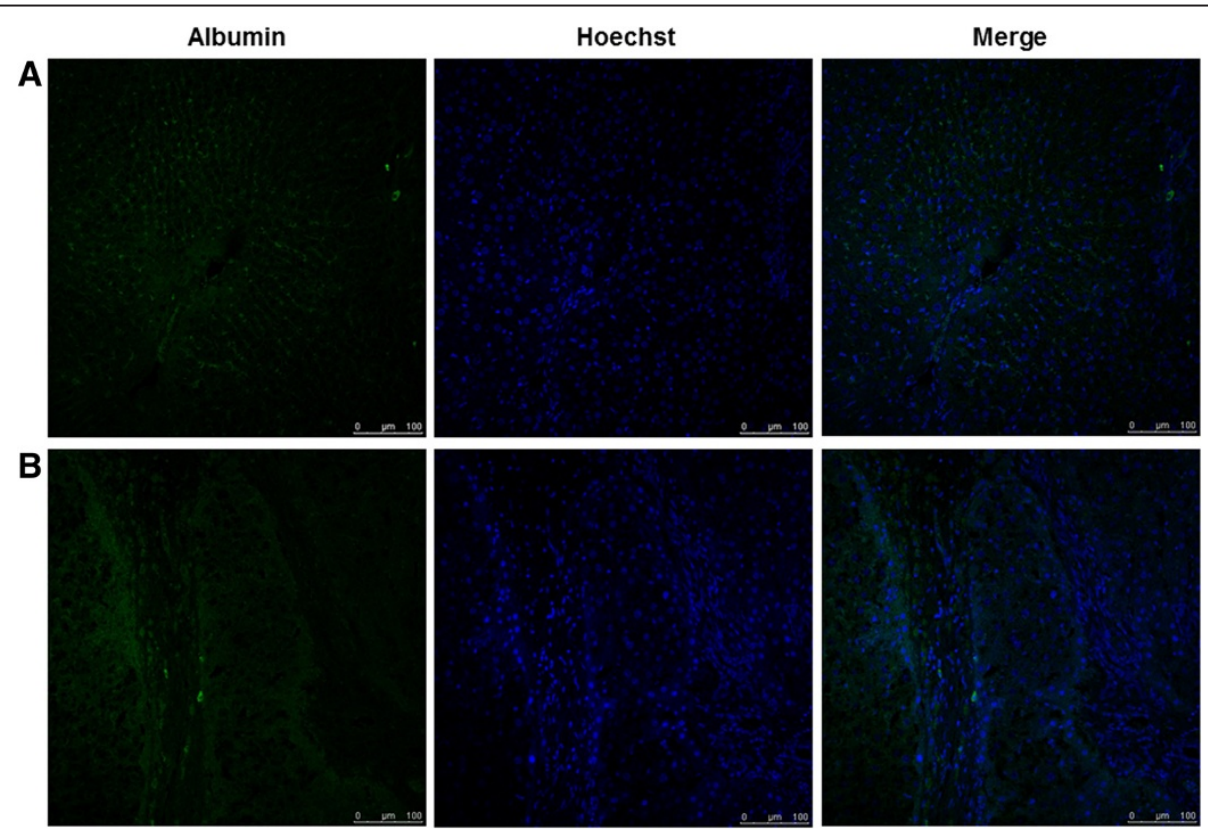

Figure 4 Immunofluorescence staining for albumin expression after BM-MSCs injection by confocal microscope. Immunofluorescence image showed BM-MSCs with hepatocyte differentiation and albumin expression at 7 days (A) and 14 days (B) after BM-MSCs injection under a confocal microscope. Merged immunofluorescence images of albumin (green) and hoechst (blue). (Scale bar, $100 \mu \mathrm{m}$ ). 


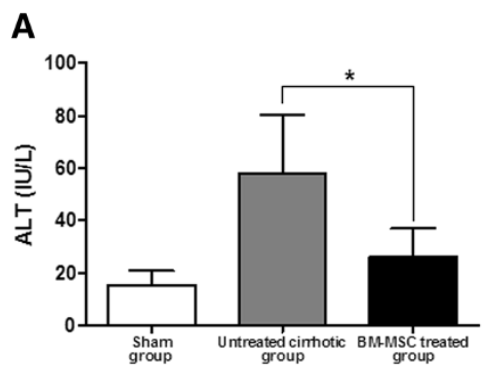

C

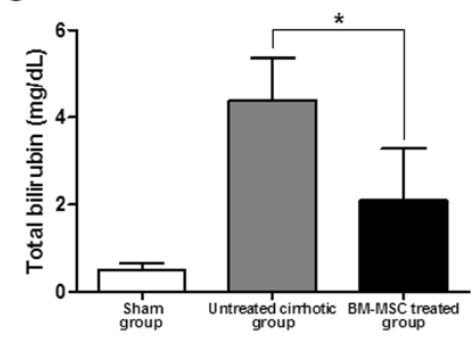

B

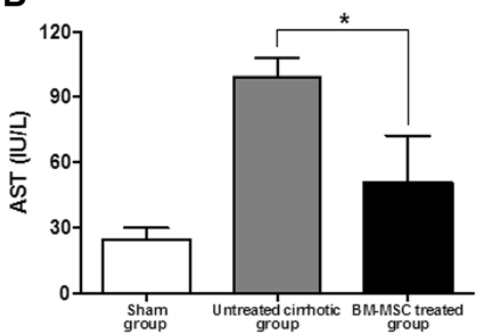

D

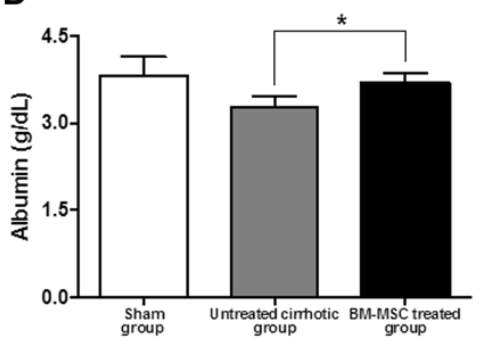

Figure 5 Effect of BM-MSCs on serum biomarkers. (A) Alanine aminotransferase (ALT), (B) aspartate aminotransferase (AST), (C) total bilirubin, and (D) albumin after injection of BM-MSCs. Values are expressed as means \pm SD. ${ }^{*} P<0.01$.

Recently, stem cell-based therapy has been proposed as a promising alternative approach for end-stage liver diseases. Stem cell therapies have shown promising benefits for hepatic fibrosis in experimental and clinical studies $[11,12,17,20]$. BM consists of two main populations of stem cells, hematopoietic stem cells and MSCs, the latter of which have been considered as alternative cell sources for liver or hepatocyte transplantation [22]. In liver damage, MSCs differentiate into hepatocytes, stimulate the regeneration of endogenous parenchymal cells, migrate to damaged sites, and enhance fibrous matrix degradation (antifibrotic effects). A recent study suggested that MSCs
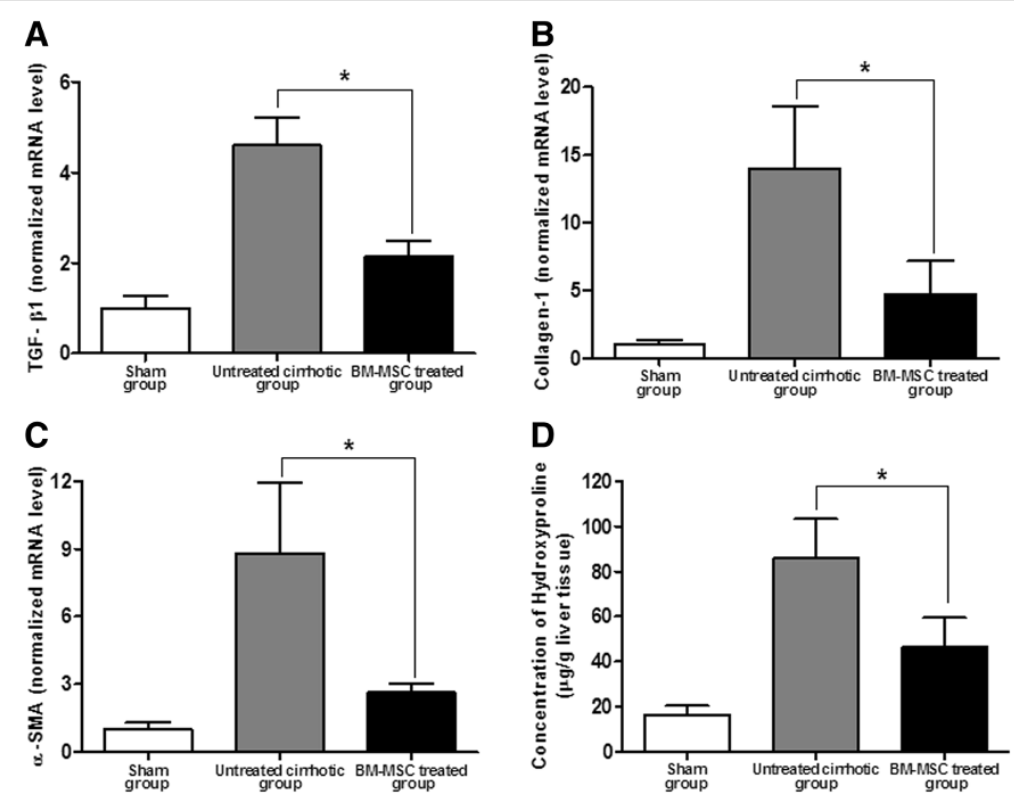

Figure 6 TGF- $\beta 1$, collagen-1, and $\alpha$-SMA mRNA levels and measurement of hepatic hydroxyproline content. After BM-MSC administration, the mRNA relative expression levels of TGF- $\beta 1$ (A), collagen-1 (B), and a-SMA (C) through quantitative real-time PCR were significantly decreased $1 \pm 0.27,4.61 \pm 0.61$, and $2.14 \pm 0.35(P<0.01)$ and $1 \pm 0.39,14.04 \pm 4.54$, and $4.74 \pm 2.46(P<0.01)$ and $1 \pm 0.32,8.83 \pm 3.12$, and $2.62 \pm 0.41(P<0.01)$ in G1, G2, and G3, respectively. (D) Measurement of hepatic hydroxyproline content was quantified colorimetrically from liver tissues. Quantitative analysis showed that the contents of hepatic hydroxyproline of the liver tissue were $16.44 \pm 4.07,85.81 \pm 17.62$, and $46.25 \pm 13.19(P<0.01)$ in G1, $\mathrm{G} 2$, and G3, respectively. Values are expressed as means $\pm \mathrm{SD}$. ${ }^{*} P<0.01$. 

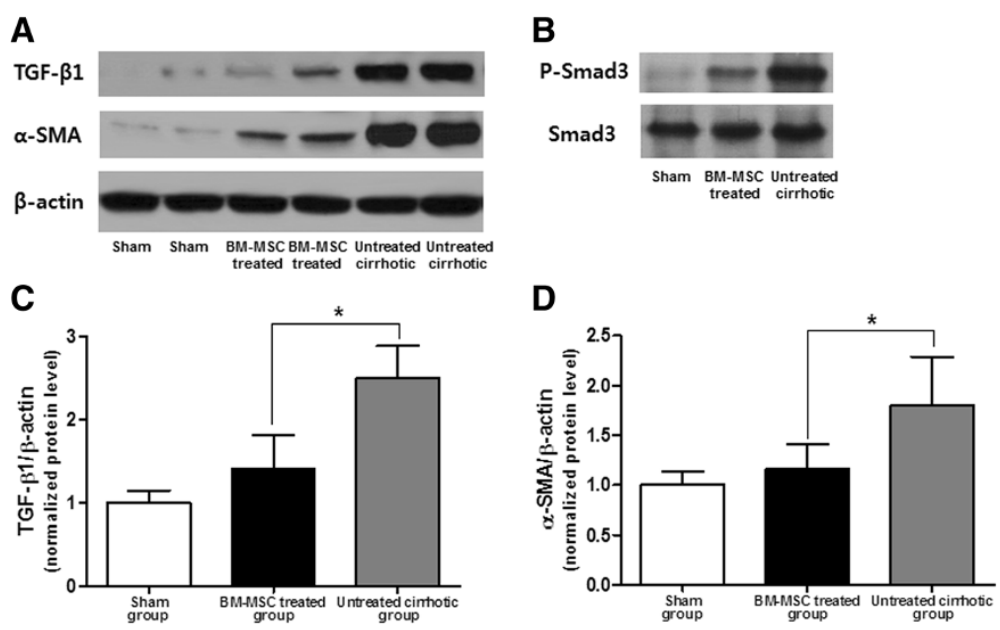

Figure 7 TGF- $\beta$ 1, $\boldsymbol{\alpha}$-SMA, and Smad3 protein expression levels. After BM-MSC administration, the TGF- $\beta 1$ ( $\mathbf{A}, \mathbf{C})$ and $a-S M A(\mathbf{A}, \mathbf{D})$ protein expression levels through western blot assays were significantly decreased $1 \pm 0.15,2.5 \pm 0.39$, and $1.41 \pm 0.41(P<0.01)$ and $1 \pm 0.14,1.8 \pm 0.49$, and $1.16 \pm 0.25(P<0.01)$ in $\mathrm{G} 1, \mathrm{G} 2$ and $\mathrm{G} 3$, respectively. (B) Phosphorylation of Smad3 was assessed through western blot assays. Values are expressed as means \pm SD. ${ }^{*} P<0.01$.

have antifibrotic effects on the injured liver in animal models of liver fibrosis [37]. Consistent with these results, we showed that the administration of BM-MSCs ameliorated hepatic fibrosis.

TAA-induced cirrhosis is a well-known classical experimental cirrhosis model [38,39]. In our study, we confirmed that TAA administration resulted in deficiencies in liver function and a progressive increase in collagen accumulation in the liver with periportal cirrhosis characterized by portal-portal fibrous septa surrounding the hepatic lobules.

Cirrhosis and advanced fibrosis are generally considered irreversible conditions, even after the removal of the hepatic injury. Through histological H\&E and MTC, and $\alpha$-SMA staining, we showed that BM-MSC administration resulted in significant improvement of hepatic fibrosis compared to the untreated cirrhotic group. There was a clear histological variability of severity within cirrhosis classified as F4 by the METAVIR system. Cirrhosis is currently considered potentially reversible if the cause of the injury is removed. The lack of subclassification within cirrhosis can be problematic when assessing the antifibrotic effect of agents such as antiviral drugs. For instance, even though antifibrotic therapy leads to the improvement of hepatic fibrosis from F4C to F4A in the Laennec system, the lack of change under the conventional METAVIR system may lead to the false conclusion that treatment is ineffective. Hence, further histological subclassification of cirrhosis is required $[4,35]$. In this study, we applied the new Laennec fibrosis scoring system to provide a more detailed classification of F4 cirrhosis.
According to this scoring system, histological improvement was observed in hepatic fibrosis after BM-MSC treatment $(P<0.01)$. These results were confirmed by immunohistochemical assays revealing $\alpha$-SMA expression and Picrosirius Red staining. In addition, the percentage of the collagen proportionate area and the content of hepatic hydroxyproline significantly decreased after BM-MSC treatment. These results indicated that BM-MSCs improved liver structure in TAA-induced cirrhotic rats.

TGF- $\beta 1$ is a primary mediator particularly in liver fibrogenesis. TGF- $\beta 1$ promotes HSCs to transition into MFBs; it also stimulates the synthesis of ECM factors such as collagen-1 and inhibits its degradation [40]. Furthermore, the expression of $\alpha$-SMA in the liver is an indicator of HSC activation, which is recognized as a key player in hepatic fibrosis and cirrhosis [41]. Likewise, this study showed that BM-MSCs recovered liver function, as indicated by decreased TGF- $\beta 1$, collagen- 1 , and $\alpha$-SMA gene expression. Furthermore, $\alpha$-SMA protein expression significantly decreased after BM-MSC treatment. The results of our study are in agreement with those of Campbell JS et al. [42]. Indeed, the activation of TGF- $\beta /$ Smad signaling is a key mechanism of liver fibrosis in both experimental and human chronic liver diseases [43]. We also showed P-Smad3/Smad3, downstream effectors of the TGF- $\beta 1$ signaling pathway, and found that MSC transplantation inhibited Smad3 phosphorylation. Hence, this study has confirmed a significant inhibitory effect of BM-MSCs on TAA-induced cirrhosis in rats, which likely correlates with the TGF$\beta 1 /$ Smad signaling pathways. 


\section{Conclusions}

In conclusion, our study showed that BM-MSC treatment inhibited fibrosis formation and the progression of TAA-induced cirrhosis in rats by modulating the TGF$\beta /$ Smad signaling pathway. Therefore, BM-MSC therapy leads to the improvement of hepatic fibrosis and may provide a new strategy for antifibrosis therapy in the future.

\section{Additional file}

Additional file 1: Figure S1. Fluorescence images of injected BM-MSCs labeled with CELL-STALKER in hepatic fibrosis rat. BM-MSCs labeled with fluorescence red were showed at 0 (A), 3 (B), 7 (C), 14 (D) days after direct injection in hepatic fibrosis rats (CELL STALKER-CSR dye staining, red: Scar bar, $100 \mu \mathrm{m}$ ).

\section{Abbreviations}

BM: Bone marrow; BM-MSCs: Bone marrow-derived mesenchymal stem cells; MELD: Model for end-stage liver disease; TGF- $\beta 1$ : Transforming growth factor-beta 1; collagen-1: Type 1 collagen; a-SMA: a-smooth muscle actin; GAPDH: Glyceraldehyde-3-phosphate dehydrogenase; H\&E: Hematoxylin and eosin; MTC: Masson's trichrome; SD: Standard deviation.

\section{Competing interests}

The authors declare that they have no competing interests.

\section{Authors' contributions}

YOJ and MYK designed the study, performed experiments, interpreted data, and drafted the manuscript. MYC contributed to the interpretations of the data and the revision of the manuscript. SKB participated in the design of the study and contributed to the interpretations of the data and the revision of the manuscript. SOK and YZC contributed to the interpretations of the data and performed the statistical analysis. All authors read and approved the final manuscript.

\section{Acknowledgments}

This study was supported by a grant of the Korea Health Technology R\&D Project, Ministry of Health \& Welfare, Republic of Korea (No. A100054) and also by the Yonsei University Future-leading Research Initiative of 2014.

\section{Author details}

'Department of Internal Medicine, Yonsei University, Wonju College of Medicine, 162, Ilsan-dong, Wonju, Republic of Korea. ${ }^{2}$ Department of Pathology, Yonsei University, Wonju College of Medicine, 162, Ilsan-dong, Wonju, Republic of Korea.

Received: 7 May 2014 Accepted: 6 November 2014 Published online: 25 November 2014

\section{References}

1. Bolondi L, Gramantieri L: From liver cirrhosis to HCC. Intern Emerg Med 2011, 6(Suppl 1):93-98

2. Iredale JP: Cirrhosis: new research provides a basis for rational and targeted treatments. BMJ 2003, 327(7407):143-147.

3. Kim MY, Baik SK, Yea CJ, Lee IY, Kim HJ, Park KW, Kim HK, Suk KT, Kim JW, Kim HS, Kwon SO, Cha SH, Kim YJ, Koh SB, Chang SJ: Hepatic venous pressure gradient can predict the development of hepatocellular carcinoma and hyponatremia in decompensated alcoholic cirrhosis. Eur J Gastroenterol Hepatol 2009, 21(11):1241-1246.

4. Kim MY, Suk KT, Baik SK, Kim HA, Kim YJ, Cha SH, Kwak HR, Cho MY, Park HJ, Jeon HK, Park SY, Kim BR, Hong JH, Jo KW, Kim JW, Kim HS, Kwon SO, Chang SJ, Baik GH, Kim DJ: Hepatic vein arrival time as assessed by contrast-enhanced ultrasonography is useful for the assessment of portal hypertension in compensated cirrhosis. Hepatology 2012 56(3):1053-1062

5. Lee SS, Shin HS, Kim HJ, Lee SJ, Lee HS, Hyun KH, Kim YH, Kwon BW, Han JH, Choi H, Kim BH, Lee JH, Kang HY, Shin HD, Song $H$ : Analysis of prognostic factors and 5-year survival rate in patients with hepatocellular carcinoma: a single-center experience. Korean J Hepatol 2012, 18(1):48-55.

6. Moon KM, Kim G, Baik SK, Choi E, Kim MY, Kim HA, Cho MY, Shin SY, Kim JM, Park HJ, Kwon SO, Eom YW: Ultrasonographic scoring system score versus liver stiffness measurement in prediction of cirrhosis. Clin Mol Hepatol 2013, 19(4):389-398.

7. Singal AK, Duchini A: Liver transplantation in acute alcoholic hepatitis: Current status and future development. World J Hepatol 2011, 3(8):215-218.

8. Strom SC, Bruzzone P, Cai H, Ellis E, Lehmann T, Mitamura K, Miki T: Hepatocyte transplantation: clinical experience and potential for future use. Cell Transplant 2006, 15(Suppl 1):S105-S110.

9. Strom S, Fisher R: Hepatocyte transplantation: new possibilities for therapy. Gastroenterology 2003, 124(2):568-571.

10. Kakinuma S, Nakauchi H, Watanabe M: Hepatic stem/progenitor cells and stem-cell transplantation for the treatment of liver disease. J Gastroenterol 2009, 44(3):167-172

11. Kharaziha P, Hellstrom PM, Noorinayer B, Farzaneh F, Aghajani K, Jafari F, Telkabadi M, Atashi A, Honardoost M, Zali MR, Soleimani M: Improvement of liver function in liver cirrhosis patients after autologous mesenchymal stem cell injection: a phase I-II clinical trial. Eur J Gastroenterol Hepatol 2009, 21(10):1199-1205.

12. Cho KA, Lim GW, Joo SY, Woo SY, Seoh JY, Cho SJ, Han HS, Ryu KH: Transplantation of bone marrow cells reduces $\mathrm{CCl} 4$-induced liver fibrosis in mice. Liver int 2011, 31(7):932-939.

13. Sakaida I, Terai S, Yamamoto N, Aoyama K, Ishikawa T, Nishina H, Okita K Transplantation of bone marrow cells reduces $\mathrm{CCl} 4$-induced liver fibrosis in mice. Hepatology 2004, 40(6):1304-1311.

14. Hardjo M, Miyazaki M, Sakaguchi M, Masaka T, Ibrahim S, Kataoka K, Huh $\mathrm{NH}$ : Suppression of carbon tetrachloride-induced liver fibrosis by transplantation of a clonal mesenchymal stem cell line derived from rat bone marrow. Cell Transplant 2009, 18(1):89-99.

15. Higashiyama $R$, Inagaki $Y$, Hong $Y Y$, Kushida $M$, Nakao $S$, Niioka $M$, Watanabe T, Okano H, Matsuzaki Y, Shiota G, Okazaki I: Bone marrowderived cells express matrix metalloproteinases and contribute to regression of liver fibrosis in mice. Hepatology 2007, 45(1):213-222.

16. Mormone E, George J, Nieto N: Molecular pathogenesis of hepatic fibrosis and current therapeutic approaches. Chem Biol Interact 2011, 193(3):225-231.

17. Pai M, Zacharoulis D, Milicevic MN, Helmy S, Jiao LR, Levicar N, Tait P, Scott M, Marley SB, Jestice K, Glibetic M, Bansi D, Khan SA, Kyriakou D, Rountas C, Thillainayagam A, Nicholls JP, Jensen S, Apperley JF, Gordon MY, Habib NA: Autologous infusion of expanded mobilized adult bone marrow-derived CD34+ cells into patients with alcoholic liver cirrhosis. Am J Gastroenterol 2008, 103(8):1952-1958.

18. Rockey DC: Current and future anti-fibrotic therapies for chronic liver disease. Clin Liver Dis 2008, 12(4):939-962. xi.

19. Sakaida I, Terai S, Nishina H, Okita K: Development of cell therapy using autologous bone marrow cells for liver cirrhosis. Med Mol Morphol 2005, 38(4):197-202

20. Terai S, Ishikawa T, Omori K, Aoyama K, Marumoto Y, Urata Y, Yokoyama Y, Uchida K, Yamasaki T, Fujii Y, Okita K, Sakaida I: Improved liver function in patients with liver cirrhosis after autologous bone marrow cell infusion therapy. Stem Cells 2006, 24(10):2292-2298.

21. am Esch JS 2nd, Knoefel WT, Klein M, Ghodsizad A, Fuerst G, Poll LW, Piechaczek C, Burchardt ER, Feifel N, Stoldt V, Stockschläder M, Stoecklein N, Tustas RY, Eisenberger CF, Peiper M, Häussinger D, Hosch SB: Portal application of autologous CD133+ bone marrow cells to the liver: a novel concept to support hepatic regeneration. Stem Cells 2005, 23(4):463-470.

22. van Poll D, Parekkadan $B$, Cho $C H$, Berthiaume $F$, Nahmias $Y$, Tilles AW, Yarmush ML: Mesenchymal stem cell-derived molecules directly modulate hepatocellular death and regeneration in vitro and in vivo. Hepatology 2008, 47(5):1634-1643.

23. Sun CK, Chen CH, Kao YH, Yuen CM, Sheu JJ, Lee FY, Chen YT, Kung CT, Yip HK: Bone marrow cells reduce fibrogenesis and enhance regeneration in fibrotic rat liver. J Surg Res 2011, 169(1):e15-e26.

24. Li T, Yan Y, Wang B, Qian H, Zhang X, Shen L, Wang M, Zhou Y, Zhu W, $\mathrm{Li} W, \mathrm{Xu} W$ : Exosomes derived from human umbilical cord mesenchymal stem cells alleviate liver fibrosis. Stem Cells Dev 2013, 22(6):845-854.

25. Gressner AM, Weiskirchen R: Modern pathogenetic concepts of liver fibrosis suggest stellate cells and TGF-beta as major players and therapeutic targets. J Cell Mol Med 2006, 10(1):76-99. 
26. Dooley S, ten Dijke P: TGF-beta in progression of liver disease. Cell Tissue Res 2012, 347(1):245-256.

27. Friedman SL: Mechanisms of hepatic fibrogenesis. Gastroenterology 2008, 134(6):1655-1669.

28. Inagaki Y, Higashiyama R, Higashi K: Novel anti-fibrotic modalities for liver fibrosis: molecular targeting and regenerative medicine in fibrosis therapy. J Gastroenterol Hepatol 2012, 27(Suppl 2):85-88.

29. Rosenbloom J, Mendoza FA, Jimenez SA: Strategies for anti-fibrotic therapies. Biochim Biophys Acta 2013, 1832(7):1088-1103.

30. Atoui R, Shum-Tim D, Chiu RC: Myocardial regenerative therapy: immunologic basis for the potential "universal donor cells". Ann Thorac Surg 2008, 86(1):327-334.

31. Le Blanc K, Ringden O: Immunomodulation by mesenchymal stem cells and clinical experience. J Intern Med 2007, 262(5):509-525.

32. Di Nicola M, Carlo-Stella C, Magni M, Milanesi M, Longoni PD, Matteucci P, Grisanti S, Gianni AM: Human bone marrow stromal cells suppress T-lymphocyte proliferation induced by cellular or nonspecific mitogenic stimuli. Blood 2002, 99(10):3838-3843.

33. Hu Y, Liao L, Wang Q, Ma L, Ma G, Jiang X, Zhao RC: Isolation and identification of mesenchymal stem cells from human fetal pancreas. J Lab Clin Med 2003, 141(5):342-349.

34. Martin JY, Dean DD, Cochran DL, Simpson J, Boyan BD, Schwartz Z: Proliferation, differentiation, and protein synthesis of human osteoblast-like cells (MG63) cultured on previously used titanium surfaces. Clin Oral Implants Res 1996, 7(1):27-37.

35. Kim MY, Cho MY, Baik SK, Park HJ, Jeon HK, Im CK, Won CS, Kim JW, Kim HS, Kwon SO, Eom MS, Cha SH, Kim YJ, Chang SJ, Lee SS: Histological subclassification of cirrhosis using the Laennec fibrosis scoring system correlates with clinical stage and grade of portal hypertension. $J$ Hepatol 2011, 55(5):1004-1009.

36. Calvaruso V, Burroughs AK, Standish R, Manousou P, Grillo F, Leandro G, Maimone S, Pleguezuelo M, Xirouchakis I, Guerrini GP, Patch D, Yu D, O'Beirne J, Dhillon AP: Computer-assisted image analysis of liver collagen: relationship to Ishak scoring and hepatic venous pressure gradient. Hepatology 2009, 49(4):1236-1244.

37. Abdel Aziz MT, Atta HM, Mahfouz S, Fouad HH, Roshdy NK, Ahmed HH, Rashed LA, Sabry D, Hassouna AA, Hasan NM: Therapeutic potential of bone marrow-derived mesenchymal stem cells on experimental liver fibrosis. Clin Biochem 2007, 40(12):893-899.

38. Li X, Benjamin IS, Alexander B: Reproducible production of thioacetamideinduced macronodular cirrhosis in the rat with no mortality. J Hepatol 2002, 36(4):488-493.

39. Tsukamoto H, Matsuoka M, French SW: Experimental models of hepatic fibrosis: a review. Semin Liver Dis 1990, 10(1):56-65.

40. Wrana JL: Transforming growth factor-beta signaling and cirrhosis. Hepatology 1999, 29(6):1909-1910.

41. Friedman SL: Seminars in medicine of the Beth Israel Hospital, Boston. The cellular basis of hepatic fibrosis. Mechanisms and treatment strategies. N Engl J Med 1993, 328(25):1828-1835.

42. Campbell JS, Hughes SD, Gilbertson DG, Palmer TE, Holdren MS, Haran AC, Odell MM, Bauer RL, Ren HP, Haugen HS, Yeh MM, Fausto N: Platelet-derived growth factor $\mathrm{C}$ induces liver fibrosis, steatosis, and hepatocellular carcinoma. Proc Natl Acad Sci U S A 2005, 102(9):3389-3394.

43. Inagaki $Y$, Okazaki I: Emerging insights into Transforming growth factor beta Smad signal in hepatic fibrogenesis. Gut 2007, 56(2):284-292.

doi:10.1186/s12876-014-0198-6

Cite this article as: Jang et al: Effect of bone marrow-derived mesenchymal stem cells on hepatic fibrosis in a thioacetamide-induced cirrhotic rat model. BMC Gastroenterology 2014 14:198.

\section{Submit your next manuscript to BioMed Central and take full advantage of:}

- Convenient online submission

- Thorough peer review

- No space constraints or color figure charges

- Immediate publication on acceptance

- Inclusion in PubMed, CAS, Scopus and Google Scholar

- Research which is freely available for redistribution

Submit your manuscript at www.biomedcentral.com/submit
Biomed Central 